Website: https://journal.stiba.ac.id

ISSN : 2685-7537 (online) 2338-5251 (Printed)

\title{
INKLUSIFITAS KEUANGAN SYARIAH \\ DAN KEMISKINAN DI INDONESIA
}

\author{
Azwar Iskandar \\ Staf Pengajar Badan Pendidikan dan Pelatihan Keuangan \\ Email: azwar.iskandar@gmail.com
}

Bayu Taufiq Possumah

Dosen Universiti Malaysia Trengganu Malaysia

Email : btaufiq@gmail.com

\begin{tabular}{|c|c|}
\hline Keywords : & ABSTRACT \\
\hline $\begin{array}{l}\text { inklusif, keuangan, syariah, } \\
\text { kemiskinan }\end{array}$ & $\begin{array}{l}\text { This paper aims at calculating and analyzing the Index of Syariah } \\
\text { Financial Inclusion (ISFI) during the period of 2015-2018 and its } \\
\text { correlation with poverty level in Indonesia. Using the secondary data } \\
\text { of } 33 \text { provinces in Indonesia from Badan Pusat Statistik (BPS), } \\
\text { Bank Indonesia and Otoritas Jasa Kenangan (OJK) and Index of } \\
\text { Financial Inclusion (IFI) method, this paper found that the Index of } \\
\text { Syariah Financial Inclusion is generally low and DKI Jakarta is the } \\
\text { most financially inclusive province of Indonesia. Furthermore, the } \\
\text { results show that the Index of Syariah Financial Inclusion is negatively } \\
\text { correlated with the poverty level. This conclusion suggests the promotion } \\
\text { of Syariah Financial Inclusion to be a policy priority in Indonesia to } \\
\text { achieve the central goals of inclusive growth, welfare and economic } \\
\text { development. }\end{array}$ \\
\hline
\end{tabular}


NUKHBATUL 'ULUM : Jurnal Bidang Kajian Islam

Vol. 4, No. 2 (2018) : Hal. 105-119

Website: https://journal.stiba.ac.id

ISSN : 2685-7537 (online) 2338-5251 (Printed)

\section{PENDAHULUAN}

Isu-isu sosial yang berkaitan dengan kemiskinan dan kesenjangan ekonomi/pendapatan (income inequality) masih menjadi perhatian banyak negara dan organisasi kerjasama baik regional, multilateral maupun internasional seperti G20, Asia-Pacific Economic Cooperation (APEC), Organisation for Economic Co-operation and Development (OECD), World Bank, Asian Development Bank (ADB) dan ASEAN. Berbagai kebijakan dirumuskan untuk mengatasi permasalahan tersebut. Salah satu upaya yang dilakukan oleh Forum G20 untuk mengentaskan kemiskinan dan menurunkan disparitas pendapatan masyarakat adalah melalui sistem keuangan yang inklusif (financial inclusion). Untuk itu, pada tanggal 1 September 2016, Presiden Joko Widodo telah menandatangani Peraturan Presiden (Perpres) Nomor 82 Tahun 2016 tentang Strategi Nasional Keuangan Inklusif (SNKI). Perpres SNKI ini dikeluarkan dalam rangka memperluas akses masyarakat terhadap layanan keuangan dan menjadi pedoman langkah-langkah strategis kementerian/lembaga untuk mendorong pertumbuhan ekonomi dan percepatan penanggulangan kemiskinan.

Peran perbankan nasional sebagai lembaga intermediasi keuangan bagi masyarakat memegang peranan yang vital dalam mewujudkan program nasional ini. Perbankan syariah sebagai bagian dalam industri perbankan nasional, dengan karakteristiknya yang khusus memiliki potensi yang besar untuk memberikan kontribusi dalam mewujudkan inklusifitas keuangan nasional. Perbankan dan industri keuangan syariah secara umum ditantang untuk memberikan perannya. Apalagi hal ini dikuatkan dengan hasil survei oleh Otoritas Jasa Keuangan (OJK) pada tahun 2016 yang menemukan bahwa meskipun mayoritas penduduk Indonesia merupakan umat muslim, tingkat literasi dan keuangan inklusif syariah masih jauh dari maksimal. Hasil ini tentu saja menjadi catatan penting bagi peningkatan peran perbankan dan industri keuangan syariah saat ini. Halim Alamsyah ${ }^{1}$, dalam Seminar Nasional Keuangan Inklusif tahun 2014, mengemukakan bahwa keuangan syariah dan kebijakan keuangan inklusif memiliki potensi untuk bersinergi dengan baik, mengingat kesamaan konsep yaitu keuangan inklusif bertujuan memberikan akses keuangan yang mudah, murah, aman dan sesuai bagi masyarakat unbanked, serta bertujuan untuk meningkatkan kapabilitas masyarakat agar mampu hidup lebih sejahtera dan keluar dari garis kemiskinan. Sementara prinsip syariah bertujuan untuk menyejahterakan masyarakat melalui prinsip partnership (musyarakah) dan profit sharing (mudharabah).

Oleh karena itu, mengingat peranan inklusifitas sektor keuangan menjadi sangat penting bagi pertumbuhan ekonomi, khususnya pada masalah sosial bangsa berupa kemiskinan dan kesenjangan ekonomi, kajian terkait inklusifitas keuangan syariah di Indonesia terhadap upaya pengentasan kemiskinan dan kesenjangan ekonomi sebagaimana semangat atau ruh ekonomi/keuangan Islam, seyogyanya menjadi agenda yang

${ }^{1}$ http://mysharing.co/keuangan-syariahdan-keuangan-inklusif-bisa-bersinergi/.Diakses pada tanggal 17 Desember 2018. 
sangat penting dan menarik untuk dilakukan baik oleh para peneliti dan pemegang kebijakan terkait. Selain itu, kajian ilmiah yang berfokus pada masalah ini di Indonesia dirasakan masih sangat minim dan menjadi salah satu poin yang dapat menyebabkan upaya pemerintah dalam upaya ini menjadi kurang optimal karena pemahaman dan wawasan tentang dinamikanya relatif terbatas.

Untuk menjembatani gap tersebut di atas, penelitian ini bertujuan untuk mengukur tingkat inklusifitas sektor perbankan syariah dan menganalisis hubungannya terhadap tingkat kemiskinan di Indonesia. Sehubungan dengan tujuan tersebut, permasalahan yang akan dijawab pada penelitian ini dirumuskan sebagai berikut:

1. Bagaimana tingkat inklusifitas sektor perbankan syariah baik secara nasional maupun pada tingkat provinsi di Indonesia?

2. Bagaimana hubungan antara inklusifitas keuangan syariah dan tingkat kemiskinan di Indonesia?

Dalam dokumen Strategi Nasional Keuangan Inklusif, keuangan inklusif didefinisikan sebagai kondisi dimana setiap orang memeiliki hak untuk memiliki akses dan layanan penuh dari lembaga keuangan secara tepat waktu, nyaman, informatif, dan terjangkau biayanya, dengan penghormatan penuh kepada harkat dan martabatnya. Layanan keuangan tersedia bagi seluruh segmen masyarakat, dengan perhatian khusus kepada orang miskin, orang miskin produktif, pekerja migrant, dan penduduk di daerah terpencil (Bank Indonesia, 2014).

Di Indonesia, keuangan inklusif menjadi strategi nasional untuk mendorong pertumbuhan ekonomi melalui distribusi pendapatan yang merata, penurunan tingkat kemiskinan, dan stabilitas sistem keuangan (Hadad, 2010). Hak setiap individu dijamin untuk dapat mengakses seluruh cakupan kualitas jasa keuangan dengan biaya yang terjangkau. Target dari kebijakan ini sangat memperhatikan masyarakat miskin berpendapatan rendah, masyarakat miskin produktif, pekerja migran, dan masyarakat yang hidup di pelosok (Bank Indonesia, 2014) Sederhananya, beberapa penelitian yang ada saat ini telah menghubungkan paling tidak tiga poin keuangan inklusif yaitu akses, kelompok masyarakat, dan sistem keuangan (Demirgüç-Kunt et al., 2008; Sarma dan Pais, 2008; Sarma, 2008; Demirgüç-Kunt dan Klapper, 2012). Strategi keuangan inklusif di Indonesia bukanlah sebuah inisiatif yang terisolasi, sehingga keterlibatan dalam keuangan inklusif tidak hanya terkait dengan tugas Bank Indonesia, namun juga regulator, kementerian dan lembaga lainnya dalam upaya pelayanan keuangan kepada masyarakat luas. Melalui strategi nasional keuangan inklusif diharapkan kolaborasi antar lembaga pemerintah dan pemangku kepentingan tercipta secara baik dan terstruktur.

Bank Indonesia menetapkan Indeks Keuangan Inklusif (IKI) sebagai salah satu cara alternatif untuk pengukuran keuangan inklusif yang menggunakan indeks multidimensional berdasarkan data makroekonomi, terutama pada jangkauan layanan sektor perbankan. Pengukuran IKI pada dasarnya merupakan upaya yang dilakukan Bank Indonesia untuk mengkombinasikan berbagai indikator sektor perbankan, sehingga pada akhirnya IKI dapat menggabungkan beberapa informasi mengenai berbagai 
Website: https://journal.stiba.ac.id

ISSN : 2685-7537 (online) 2338-5251 (Printed)

dimensi dari sebuah sistem keuangan yang inklusif, yaitu akses (access), penggunaan (usage) dan kualitas (quality) dari layanan perbankan. Sementara dalam literatur lainnya, seperti pada Sarma (2012), Gupta et. al. (2014), dan Sanjaya dan Nursechafia (2016), menggunakan indikator atau dimensi pengukuran pada metode perhitungan Index Financial Inclusion (IFI) berupa aksesibilitas (penetration), availabilitas (availability) dan penggunaan jasa perbankan (usage of banking services). Dimensi penetrasi diwakili oleh jumlah rekening deposit per 1.000 jumlah orang dewasa, dimensi availibilitas diwakili oleh jumlah bank outlets per 1000 jumlah penduduk dan/atau jumlah ATM per 1000 jumlah penduduk, dan dimensi penggunaan diwakili oleh rasio volume dari two basic services of the banking system yaitu credit dan depositdari jumlah penduduk dewasa terhadap nilai Gross Domestic Product (GDP).

$\begin{array}{lr}\text { Kesejahteraan } & \begin{array}{r}\text { dengan } \\ \text { sistem }\end{array} \\ \text { menerapkan } & \end{array}$
ekonomi/keuangan islam adalah sistem yang menganut dan memasukkan nilainilai, dogma, norma, dan ajaran islam (keimanan) sebagai unsur yang fundamental dalam mencapai kesejahteraan. Variabel keimanan tersebut sebagai tolak ukur untuk menentukan tindakan ekonomi dalam mengelola faktor produksi, konsumsi dan distribusi barang dan jasa sebelum memasukkan dalam sirkulasi hukum pasar. Sehingga terjalin keselarasan dan keseimbangan antara kepentingan individu, kelompok dengan hukum pasar yang di formulasikan melalui berbagai hasil kebijakan lembaga sosial ekonomi masyarakat dan negara dalam bentuk kebijakan yang berasaskan nilainilai keimanan. Sehingga terjalin suatu stimulasi dan sosialisasi ekonomi yang komprehensif yang dapat mengantarkan Individu dan masyarakat untuk mewujudkan kesejahteraan yang baik dan terhormat (hayatan-thayyibah) dunia dan akhirat. Penerapan beberapa sistem ekonomi baik sistem ekonomi kapitalis maupun sosialis, diharapkan akan mampu mewujudkan dan meningkatkan kesejahteraan bagi seluruh masyarakat serta mewujudkan ketentraman bagi manusia. Akan tetapi sejarah mencatat terjadi banyak kegagalan atas sistem ekonomi yang diterapkan bahkan menimbulkan banyak permasalahan di tengah masyarakat bahkan negara. Dengan kata lain, sistem ini belum berhasil memeratakan kesejahteraan rakyat malah memperburuk rakyat ke dalam kemiskinan, hal ini dapat terjadi karena dominasi pemerintah yang berlebihan yang membuat roda perekonomian tidak berkembang.

Sistem ekonomi Islam tampil dan memiliki sikap yang moderat (alwasathiyyah). Sistem ekonomi Islam tidak menzalimi kaum lemah sebagaimana terjadi pada masyarakat sistem kapitalis, tetapi juga tidak menzalimi hak individu dan kelompok kaya sebagaimana ada pada sistem sosialis-komunis. Sistem ekonomi Islam berada pada posisi tengah dan seimbang antara keduanya. Sistem ekonomi Islam memiliki peluang untuk kembali tampil memberikan solusi terhadap permasalahan ekonomi yang ada untuk mensejahterakan masyarakat. Kesejahteraan menurut Imam al-Ghazali adalah tercapainya kemaslahatan. Kemaslahatan sendiri merupakan terpeliharanya tujuan syara' (al-maqasid as-syari'ab). Manusia tidak dapat merasakan kebahagiaan dan kedamaian batin melainkan setelah tercapainya kesejahteraan yang sebenarnya dari seluruh umat manusia 
NUKHBATUL 'ULUM : Jurnal Bidang Kajian Islam

Vol. 4, No. 2 (2018) : Hal. 105-119

Website: https://journal.stiba.ac.id

ISSN : 2685-7537 (online) 2338-5251 (Printed)

Tabel 1. Definisi Operasional Variabel

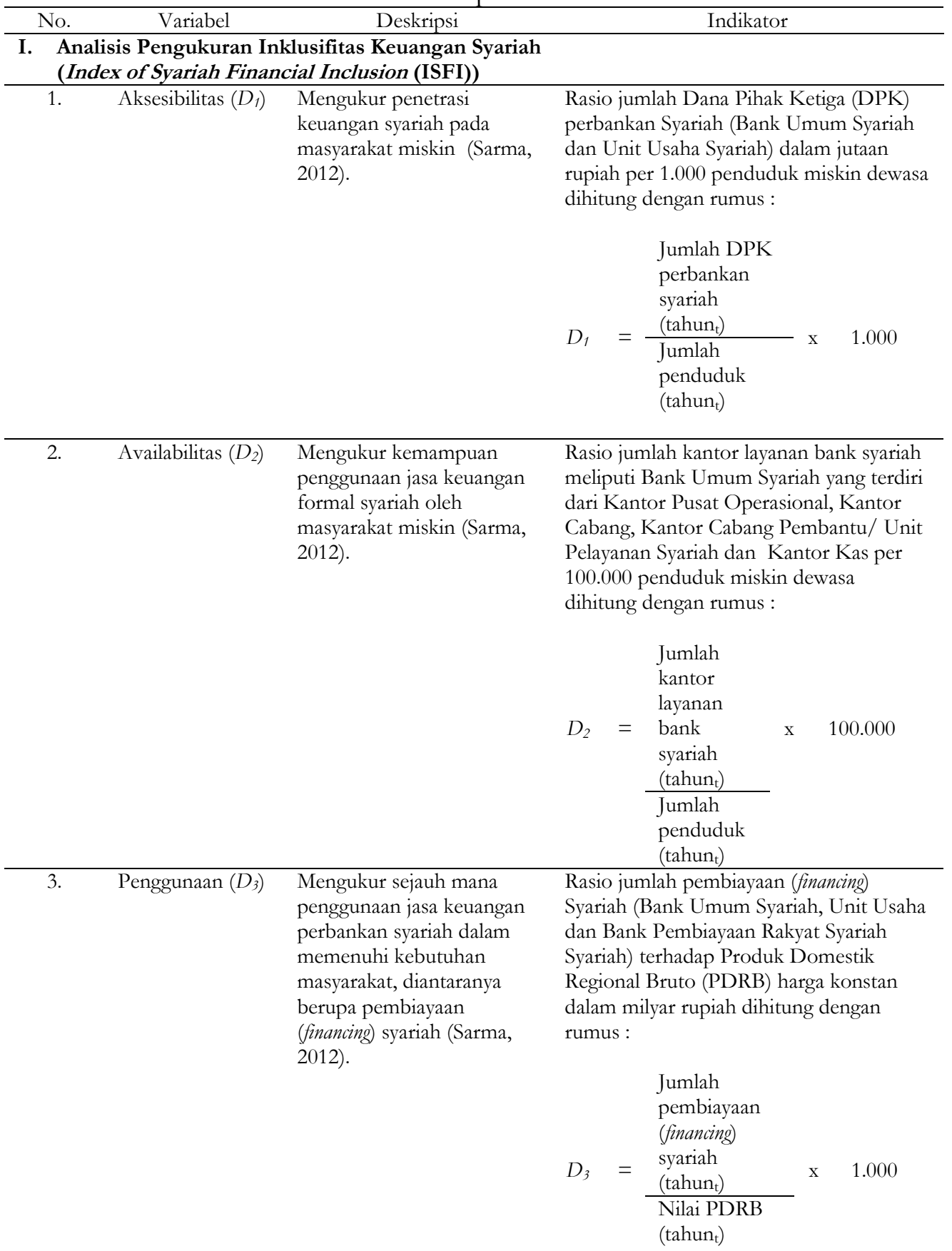

\begin{tabular}{lcc}
\hline II. & Analisis Pengaruh Inklusifitas Keuangan Syariah terhadap Kemiskinan \\
\hline 1. & $\begin{array}{l}\text { Indeks Keuangan } \\
\text { Inklusif Syariah }\end{array}$ & Nilai indeks hasil perhitungan keuangan inklusif syariah. \\
2. & Kemiskinan & Persentase jumlah penduduk miskin untuk perkotaan dan pedesaan \\
\hline
\end{tabular}
Sumber: BPS (2018), Bank Indonesia (2018)

di dunia melalui pemenuhan kebutuhan-kebutuhan ruhani dan materi. Untuk mencapai tujuan syara' agar dapat terealisasinya kemaslahatan, beliau menjabarkan tentang sumbersumber kesejahteraan, yakni 
Website: https://journal.stiba.ac.id

ISSN : 2685-7537 (online) 2338-5251 (Printed)

terpeliharanya agama, jiwa, akal, keturunan dan harta. ${ }^{2}$

Penelitian ini menggunakan data sekunder berbentuk time series berbasis tahunan periode tahun 2016$2018^{3}$ dan cross-section pada 33 provinsi di Indonesia yang bersumber dari Badan Pusat Statistik (BPS), Bank Indonesia dan OJK. Mengingat bahwa penelitian ini menggunakan metode Indeks Keuangan inklusif atau Index of Financial Inclusion (IFI) yang dikembangkan oleh Sarma (2012) dalam menganalisis dan mengukur keuangan inklusif syariah di Indonesia, maka variabel penelitian yang digunakan mengacu pada dimensi pengukuran IFI yaitu aksesibilitas $\left(D_{1}\right)$, availabilitas $\left(D_{2}\right)$, dan penggunaan $\left(D_{3}\right)$. Adapun terkait dengan analisis hubungan inklusifitas keuangan syariah terhadap kemiskinan dan kesenjangan ekonomi, penelitian ini menggunakan beberapa variabel yang dipilih yaitu persentase jumlah penduduk miskin dan Indeks Gini (Gini Ratio). Definisi operasional seluruh variabel tersebut adalah sebagai berikut:

Penelitian ini mengadopsi pengukuran Index of Financial Inclusion (IFI) yang digunakan oleh Sarma (2012). Metode ini digunakan karena menyajikan pengukuran komprehensif yang robust dan dapat dibandingkan antarprovinsi. Secara detail, langkah pertama yang dilakukan adalah menentukan nilai indeks inklusi setiap dimensi ( $\left.d_{\mathrm{i}}\right)$ menggunakan rumus berikut:

$$
d_{i}=w_{i} \frac{D_{i}-m_{i}}{M_{i}-m_{i}}
$$

di mana $w_{i}$ adalah weight attached untuk dimensi i; $D_{i}$ adalah nilai aktual dimensi i; $m_{i}$ adalah batas terendah nilai dimensi

2 Abdur Rohman, Ekonomi Al-Ghazali : Menelusuri Konsep Ekonomi Islam dalam Ihya' i; dan $M_{i}$ adalah batas tertinggi nilai dimensi i. Pada penelitian ini, bobot yang digunakan (weight attached) untuk seluruh dimensi bernilai sama $\left(w_{i}=1\right)$. Dengan merujuk ke metode yang digunakan oleh Sarma (2012), penelitian ini mengasumsikan bahwa seluruh dimensi memiliki prioritas yang sama, sehingga bobot nilainya adalah $w_{i}$ $=1$ untuk seluruh $i$. Nilai domensi yang mendekati $w_{i}$ menunjukkan area dengan capaian tertinggi pada seluruh dimensi. Sarma (2012) secara empiris melakukan pengamatan batas minimum terendah dan batas maksimum tertinggi. Tidak seperti dimensi pembangunan manusia (buman development), hal ini agak sulit untuk mengukur batas bawah dan batas atas keuangan inklusif. Namun demikian karena tidak adanya hasil outlier dalam kasus Indonesia, titik $M_{i}$ mewakili nilai maksimum dari data yang tersedia yang merupakan batas maksimum untuk setiap dimensi, sedangkan $m_{i}$ merepresentasikan batas terendah.

$$
\text { Langkah kedua adalah }
$$
menentukan nilai $X_{1}$ dan $X_{2}$ dengan menggunakan rumus di bawah ini:

$$
\begin{gathered}
X_{1}=\frac{\sqrt{d_{1}{ }^{2}+d_{2}{ }^{2}+d_{3}{ }^{2}}}{\sqrt{w_{1}{ }^{2}+w_{2}{ }^{2}+w_{3}^{2}}} \\
X_{2}=\frac{\sqrt{\left(w_{1}-d_{1}\right)^{2}+\left(w_{2}-d_{2}\right)^{2}+\left(w_{3}-d_{3}\right)^{2}}}{\sqrt{w_{1}{ }^{2}+w_{2}{ }^{2}+w_{3}{ }^{2}}} \\
\text { Langkah ketiga adalah } \\
\text { menentukan nilai IFI sebagai nilai } \\
\text { rata-rata sederhana dari } X_{1} \text { dan } X_{2} \\
\text { dengan rumus berikut: }
\end{gathered}
$$

$$
I F I=\frac{1}{2}\left[X_{1}+X_{2}\right]
$$

Seperti dijelaskan sebelumnya, nilai indeks dari setiap dimensi terletak antara 0 dan $w_{i}$. Nilai $d_{i}$ yang lebih tinggi mengindikasikan lebih banyak titik

Ulum Ad-din (Surabaya: Bina Ilmu, 2010), hlm.8486

\footnotetext{
${ }^{3}$ Data hingga September 2018
} 
Website: https://journal.stiba.ac.id

ISSN : 2685-7537 (online) 2338-5251 (Printed)

ideal pada dimensi ke $i$. Titik $\mathrm{X}=\left(d_{1}\right.$, $\left.d_{2}, d_{3}\right)$ menunjukkan pencapaian keuangan inklusif pada sebuah provinsi. Kemudian pada ruang dimensi, point $\mathrm{O}=\left(\begin{array}{lll}0, & 0,0\end{array}\right)$ merepresentasikan situasi yang terburuk, sedangkan titik $\mathrm{W}=\left(w_{1}, w_{2}\right.$, $\left.w_{3}\right)$ - di mana $w_{1}, w_{2}$, dan $w_{3}$ adalah bobot setiap dimensi - yang mewakili situasi paling ideal untuk seluruh dimensi (Sarma, 2012).

Dengan titik $W=(1,1,1)$, maka rumus akhir dari IFI adalah sebagai berikut:

$$
\begin{aligned}
& =\frac{1}{2}\left[\frac{\sqrt{d_{1}{ }^{2}+d_{2}{ }^{2}+d_{3}{ }^{2}}}{\sqrt{3}}\right. \\
& +(1 \\
& \left.\left.-\frac{\sqrt{\left(1-d_{1}\right)^{2}+\left(1-d_{2}\right)^{2}+\left(1-d_{3}\right)^{2}}}{\sqrt{3}}\right)\right]
\end{aligned}
$$

Rumus IFI didapatkan dengan menghitung rata-rata nilai $X 1$ dan $X 2$ yang merepresentasikan posisi antara titik paling buruk dan titik ideal. Hasil pengukuran IFI dibagi menjadi tiga kategori: (i) IFI rendah jika nilai IFI kurang dari 0,3 ; (ii) IFI medium jika nilai IFI berada di antara 0,3 dan 0,6, dan (iii) IFI tinggi jika nilai IFI antara 0,6 dan 1 (Sarma, 2012).

Selanjutnya, untuk melihat hubungan di antara varabel, penelitian ini menggunakan teknik analisis product moment coefficient of correlation untuk mengukur hubungan antara inkulsifitas keuangan sayariah dan kemiskinan dan kesenjangan ekonomi. Metode ini digunakan mengingat data variabel model yang digunakan berbentuk rasio. Metode ini mengadopsi penelitian yang dilakukan oleh Gupta et. al. (2014), dengan formula:

$$
r=\frac{n \sum_{i=1}^{n} X_{i} Y_{i}-\sum_{i=1}^{n} X_{i} \sum_{i=1}^{n} Y_{i}}{\sqrt{n \sum_{i=1}^{n} X_{i}^{2}-\left(\sum_{i=1}^{n} X_{i}\right)^{2} \cdot \sqrt{n \sum_{i=1}^{n} Y_{i}^{2}-\left(\sum_{i=1}^{n} Y_{i}\right)^{2}}}}
$$

$$
\begin{array}{cll}
\text { dimana: } & \\
\mathrm{r} & : & \text { nilai korelasi pearson } \\
\mathrm{X} & : & \text { average variabel Indeks } \\
& & \text { Keuangan Inklusif } \\
& \text { Syariah atau Index Syariah } \\
& & \text { Financial Inclusion (ISFI) } \\
\mathrm{Y} & : & \text { kemiskinan } \\
\mathrm{n} & : & \text { Jumlah sampel }
\end{array}
$$

\section{PEMBAHASAN}

Sebuah sistem keuangan yang inklusif harus memiliki pengguna sebanyak mungkin, oleh karena itu sistem keuangan yang inklusif harus menjangkau secara luas di antara pengguna. Proporsi dari populasi yang memiliki rekening bank merupakan sebuah ukuran untuk penetrasi perbankan. Salah satu variabel yang dapat mencerminkan ukuran ini adalah jumlah DPK di bank per 1000 penduduk dewasa. Penelitian ini menggunakan nilai DPK pada perbankan syariah yang terdiri dari Bank Umum Syariah dan Unit Usaha Syariah terhadap 1000 penduduk. Pada tahun 2015-2018, rata-rata total jumlah DPK perbankan syariah per 1000 penduduk pada tiap provinsi secara total di Indonesia adalah sekitar 17,69 juta rupiah. Dari 33 provinsi yang ada, Provinsi DKI Jakarta memiliki rata-rata jumlah DPK pada perbankan syariah tertinggi dibanding provinsi lainnya yaitu mencapai rata-rata 376 juta rupiah per 1000 penduduk (Lihat Tabel 2). 
NUKHBATUL 'ULUM : Jurnal Bidang Kajian Islam

Vol. 4, No. 2 (2018) : Hal. 105-119

Website: https://journal.stiba.ac.id

ISSN : 2685-7537 (online) 2338-5251 (Printed)

Tabel 2. Dimensi Aksesibilitas $\left(\mathrm{D}_{1}\right)$ pada 33 Provinsi di Indonesia

\begin{tabular}{|c|c|c|c|c|c|}
\hline Provinsi & 2015 & 2016 & 2017 & 2018 & Average \\
\hline Aceh & 4.94 & 19.31 & 24.80 & 28.54 & 19.40 \\
\hline Bali & 3.67 & 4.84 & 6.20 & 6.94 & 5.41 \\
\hline Bangka Belitung & 3.34 & 6.98 & 6.94 & 7.84 & 6.28 \\
\hline Banten & 8.76 & 10.26 & 15.74 & 20.06 & 13.71 \\
\hline Bengkulu & 1.81 & 1.91 & 2.38 & 2.59 & 2.17 \\
\hline DKI Jakarta & 307.48 & 349.20 & 411.87 & 438.74 & 376.82 \\
\hline Gorontalo & 1.04 & 1.06 & 1.10 & 1.31 & 1.13 \\
\hline Jambi & 3.53 & 3.99 & 4.93 & 5.23 & 4.42 \\
\hline Jawa Barat & 5.88 & 7.09 & 8.97 & 10.11 & 8.01 \\
\hline Jawa Tengah & 2.76 & 3.41 & 4.37 & 4.55 & 3.77 \\
\hline Jawa Timur & 4.14 & 4.64 & 5.95 & 6.14 & 5.22 \\
\hline Kalimantan Barat & 4.62 & 5.66 & 6.23 & 6.42 & 5.73 \\
\hline Kalimantan Selatan & 16.09 & 18.27 & 23.87 & 25.38 & 20.90 \\
\hline Kalimantan Tengah & 4.64 & 4.90 & 5.24 & 6.58 & 5.34 \\
\hline Kalimantan Timur & 20.59 & 21.61 & 24.17 & 25.08 & 22.86 \\
\hline Kepulauan Riau & 12.08 & 18.74 & 15.75 & 15.94 & 15.63 \\
\hline Lampung & 1.72 & 2.04 & 2.21 & 2.22 & 2.05 \\
\hline Maluku & 0.96 & 1.07 & 1.09 & 1.19 & 1.08 \\
\hline Maluku Utara & 5.12 & 4.97 & 5.63 & 5.60 & 5.33 \\
\hline Nusa Tenggara Barat & 1.55 & 1.85 & 2.35 & 11.42 & 4.29 \\
\hline Nusa Tenggara Timur & 0.10 & 0.10 & 0.10 & 0.11 & 0.10 \\
\hline Papua & 0.67 & 0.68 & 0.64 & 0.69 & 0.67 \\
\hline Papua Barat & 1.30 & 1.51 & 1.52 & 1.47 & 1.45 \\
\hline Riau & 6.84 & 8.61 & 10.74 & 10.94 & 9.28 \\
\hline Sulawesi Barat & 1.14 & 1.11 & 1.25 & 1.50 & 1.25 \\
\hline Sulawesi Selatan & 4.49 & 5.02 & 5.21 & 5.90 & 5.16 \\
\hline Sulawesi Tengah & 1.91 & 1.86 & 2.06 & 2.00 & 1.96 \\
\hline Sulawesi Tenggara & 1.81 & 2.01 & 2.45 & 2.90 & 2.29 \\
\hline Sulawesi Utara & 1.15 & 1.08 & 1.23 & 1.33 & 1.20 \\
\hline Sumatera Barat & 7.84 & 8.64 & 10.09 & 10.90 & 9.37 \\
\hline Sumatera Selatan & 3.78 & 4.14 & 4.77 & 5.96 & 4.66 \\
\hline Sumatera Utara & 5.55 & 7.06 & 8.92 & 9.08 & 7.65 \\
\hline Yogyakarta & 7.45 & 8.07 & 9.91 & 11.42 & 9.21 \\
\hline Average & 13.90 & 16.42 & 19.35 & 21.09 & 17.69 \\
\hline
\end{tabular}

Selain penetrasi perbankan, ukuran lain dalam sistem keuangan yang inklusif adalah ketersediaan jasa perbankan (availabilitas). Ukuran ini menggambarkan jangkauan jasa perbankan sehingga masyarakat dapat mengakses jasa keuangan di mana pun berada. Indikator dari ketersediaan jasa perbankan adalah jumlah outlet (baik itu kantor, kantor cabang, ATM, dan sebagainya). Dalam penelitian ini, ketersediaan jasa perbankan diukur dengan jumlah kantor layanan bank syariah meliputi Bank Pembiayaan Rakyat Syariah per 100.000 penduduk. Pada tahun 2016-2018, rata-rata jumlah perbankan syariah untuk melayani setiap 100.000 penduduk di seluruh provinsi di Indonesia adalah sebesar 0,1 unit atau dengan kata lain tersedia 10 unit untuk melayani 10 juta penduduk. Jumlah ini tentu saja merupakan jumlah yang sangat minim terkait dengan ketersediaan layanan perbankan syariah di daerah. Dari 33 provinsi yang ada, Provinsi DKI Jakarta menempati posisi teratas tingkat ketersediaan layanan perbankan syariah dibanding provinsi lainnya yaitu mencapai rata-rata 0,7 unit per 100.000 penduduk atau 7 unit per 1 juta penduduk (Lihat Tabel 3). 
NUKHBATUL 'ULUM : Jurnal Bidang Kajian Islam

Vol. 4, No. 2 (2018) : Hal. 105-119

Website: https://journal.stiba.ac.id

ISSN : 2685-7537 (online) 2338-5251 (Printed)

Tabel 3. Dimensi Availabilitas $\left(\mathrm{D}_{2}\right)$ pada 33 Provinsi di Indonesia

\begin{tabular}{lccccc}
\hline \multicolumn{1}{c}{ Provinsi } & 2015 & 2016 & 2017 & 2018 & Average \\
\hline Aceh & 0.05 & 0.18 & 0.19 & 0.2 & 0.15 \\
\hline Bali & 0.10 & 0.1 & 0.1 & 0.1 & 0.10 \\
\hline Bangka Belitung & 0.18 & 0.15 & 0.13 & 0.1 & 0.14 \\
\hline Banten & 0.15 & 0.14 & 0.13 & 0.14 & 0.14 \\
\hline Bengkulu & 0.06 & 0.05 & 0.05 & 0.06 & 0.05 \\
\hline DKI Jakarta & 0.78 & 0.7 & 0.64 & 0.68 & 0.70 \\
\hline Gorontalo & 0.04 & 0.03 & 0.02 & 0.03 & 0.03 \\
\hline Jambi & 0.12 & 0.09 & 0.09 & 0.1 & 0.10 \\
\hline Jawa Barat & 0.08 & 0.08 & 0.08 & 0.08 & 0.08 \\
\hline Jawa Tengah & 0.04 & 0.03 & 0.03 & 0.04 & 0.03 \\
\hline Jawa Timur & 0.05 & 0.04 & 0.04 & 0.04 & 0.04 \\
\hline Kalimantan Barat & 0.07 & 0.06 & 0.06 & 0.06 & 0.06 \\
\hline Kalimantan Selatan & 0.20 & 0.18 & 0.17 & 0.17 & 0.18 \\
\hline Kalimantan Tengah & 0.10 & 0.09 & 0.08 & 0.08 & 0.09 \\
\hline Kalimantan Timur & 0.26 & 0.24 & 0.22 & 0.22 & 0.23 \\
\hline Kepulauan Riau & 0.24 & 0.21 & 0.19 & 0.18 & 0.20 \\
\hline Lampung & 0.04 & 0.04 & 0.04 & 0.04 & 0.04 \\
\hline Maluku & 0.02 & 0.02 & 0.02 & 0.02 & 0.02 \\
\hline Maluku Utara & 0.08 & 0.08 & 0.11 & 0.11 & 0.10 \\
\hline Nusa Tenggara Barat & 0.04 & 0.04 & 0.04 & 0.09 & 0.05 \\
\hline Nusa Tenggara Timur & 0.00 & 0.00 & 0.00 & 0.00 & 0.00 \\
\hline Papua & 0.01 & 0.01 & 0.01 & 0.01 & 0.01 \\
\hline Papua Barat & 0.02 & 0.02 & 0.02 & 0.02 & 0.02 \\
\hline Riau & 0.12 & 0.1 & 0.1 & 0.1 & 0.10 \\
\hline Sulawesi Barat & 0.02 & 0.02 & 0.02 & 0.03 & 0.02 \\
\hline Sulawesi Selatan & 0.07 & 0.07 & 0.07 & 0.07 & 0.07 \\
\hline Sulawesi Tengah & 0.05 & 0.04 & 0.04 & 0.04 & 0.04 \\
\hline Sulawesi Tenggara & 0.05 & 0.05 & 0.06 & 0.06 & 0.06 \\
\hline Sulawesi Utara & 0.06 & 0.04 & 0.04 & 0.04 & 0.04 \\
\hline Sumatera Barat & 0.15 & 0.12 & 0.13 & 0.12 & 0.13 \\
\hline Sumatera Selatan & 0.06 & 0.05 & 0.05 & 0.05 & 0.05 \\
\hline Sumatera Utara & 0.07 & 0.05 & 0.06 & 0.06 & 0.06 \\
\hline Yogyakarta & 0.11 & 0.09 & 0.10 & 0.10 & 0.10 \\
\hline & 0.10 & 0.10 & 0.09 & 0.10 & 0.10 \\
\hline & $5 u m b e r:$ & 0.67 & \\
\hline
\end{tabular}

Selanjutnya, memiliki rekening di bank tidaklah cukup untuk menunjukkan sistem keuangan yang inklusif. Keberadaan jasa keuangan pun harus memiliki cukup manfaat bagi masyarakat. Manfaat bagi masyarakat dapat dalam berbagai bentuk, di anaranya berupa kredit, deposito, pembayaran, remitansi, transfer, dan lain-lain. Oleh karena itu, indikator penggunaan ini harus dimasukkan ke dalam pengukuran sistem keuangan yang inklusif. Dalam penelitian ini, indikator penggunaan dilihat dari proporsi jumlah pembiayaan (financing) syariah oleh perbankan syariah yang terdiri dari Bank Umum Syariah, Unit Usaha dan Bank Pembiayaan Rakyat Syariah ${ }^{4}$ terhadap PDRB pada tiap provinsi selama tahun 2016-2018. Hasil estimasi menemukan bahwa rata-rata penggunaan pembiayaan perbankan syariah pada periode penelitian di Indonesia adalah sebesar 268 milyar rupiah. Berbeda dengan dimensi aksesibilitas dan availibiltas, Provinsi Jawa Barat menempati posisi tertinggi

${ }^{4}$ Khusus untuk data tahun 2015, jumlah pembiayaan hanya diambil dari data BPRS. 
NUKHBATUL 'ULUM : Jurnal Bidang Kajian Islam

Vol. 4, No. 2 (2018) : Hal. 105-119

Website: https://journal.stiba.ac.id

ISSN : 2685-7537 (online) 2338-5251 (Printed)

Tabel 4. Dimensi Penggunaan $\left(\mathrm{D}_{3}\right)$ pada 33 Provinsi di Indonesia

\begin{tabular}{|c|c|c|c|c|c|}
\hline Provinsi & 2015 & 2016 & 2017 & 2018 & Average \\
\hline Aceh & 455.91 & 577.34 & 600.24 & 443.79 & 519.32 \\
\hline Bali & 19.41 & 51.61 & 47.58 & 41.67 & 40.07 \\
\hline Bangka Belitung & 944.52 & 12.98 & 11.74 & 35.04 & 251.07 \\
\hline Banten & $1,921.59$ & 201.62 & 233.16 & 78.16 & 608.63 \\
\hline Bengkulu & 407.99 & 42.49 & 46.36 & 103.35 & 150.05 \\
\hline DKI Jakarta & 8.95 & 677.63 & 781.3 & 302.21 & 442.52 \\
\hline Gorontalo & - & 14.16 & 12.63 & 37.66 & 16.11 \\
\hline Jambi & - & 58.93 & 64 & 79.33 & 50.57 \\
\hline Jawa Barat & $7,111.57$ & $1,108.84$ & $1,133.05$ & 92.81 & $2,361.57$ \\
\hline Jawa Tengah & $2,349.00$ & 600.32 & 648.33 & 79.67 & 919.33 \\
\hline Jawa Timur & $3,026.26$ & 601.44 & 645.45 & 66.23 & $1,084.85$ \\
\hline Kalimantan Barat & - & 154.55 & 162.43 & 133.04 & 112.51 \\
\hline Kalimantan Selatan & 70.63 & 135.09 & 164.95 & 131.91 & 125.65 \\
\hline Kalimantan Tengah & 21.17 & 23.34 & 34.62 & 52.61 & 32.94 \\
\hline Kalimantan Timur & 1.12 & 34.5 & 35.63 & 40.49 & 27.93 \\
\hline Kepulauan Riau & 56.32 & 43.64 & 47.1 & 89.38 & 59.11 \\
\hline Lampung & $1,011.38$ & 86.21 & 96.63 & 47.95 & 310.54 \\
\hline Maluku & - & 7.13 & 9.53 & 24.49 & 10.29 \\
\hline Maluku Utara & 83.75 & 10.86 & 13.28 & 46.07 & 38.49 \\
\hline Nusa Tenggara Barat & 795.92 & 115.94 & 158.73 & 320.78 & 347.84 \\
\hline Nusa Tenggara Timur & - & 16.01 & 13.2 & 9.74 & 9.74 \\
\hline Papua & 2.29 & 11.66 & 10.71 & 11.15 & 8.95 \\
\hline Papua Barat & - & 2.49 & 2.31 & 9.12 & 3.48 \\
\hline Riau & 159.66 & 61.41 & 73.39 & 46.56 & 85.25 \\
\hline Sulawesi Barat & - & 8.38 & 10.36 & 35.61 & 13.59 \\
\hline Sulawesi Selatan & 397.65 & 186.91 & 175.91 & 74.6 & 208.77 \\
\hline Sulawesi Tengah & - & 32.89 & 37.7 & 52.32 & 30.73 \\
\hline Sulawesi Tenggara & - & 28.2 & 30.88 & 47.94 & 26.76 \\
\hline Sulawesi Utara & - & 13.67 & 14.09 & 21.49 & 12.31 \\
\hline Sumatera Barat & 489.35 & 130.12 & 123.43 & 94.26 & 209.29 \\
\hline Sumatera Selatan & 35.70 & 131.17 & 160.62 & 82.84 & 102.58 \\
\hline Sumatera Utara & 284.31 & 281.62 & 292.05 & 82.42 & 235.10 \\
\hline Yogyakarta & $1,186.09$ & 116.27 & 129.38 & 159.3 & 397.76 \\
\hline Average & 631.53 & 169.07 & 182.45 & 90.12 & 268.29 \\
\hline
\end{tabular}

Sumber: hasil olah data

dalam penggunaan jasa perbankan syariah oleh masyarakat (Lihat Tabel 4).

Dari proporsi Indeks

Keuangan Inklusif Syariah tiga dimensi pada Tabel 5 di bawah, dimensi penggunaan memiliki nilai rata-rata (average) yang paling tinggi selama periode tahun 2015-2018, diikuti oleh dimensi availabilitas kemudian dimensi aksesibilitas. Hasil ini mengindikasikan bahwa keuangan inklusif syariah di Indonesia utamanya ditentukan oleh dimensi pengunaan dan availabilitas. Sementara dimensi aksesibilitas hanya memiliki proporsi yang relatif kecil dibanding keduanya. Selain penggunaan, dimensi availibilitas juga menunjukkan nilai indeks yang relatif baik. Hal ini menunjukkan bahwa perbankan syariah telah memberikan peran intermediasinya kepada masyarakat melalui pembiayaan syariah di berbagai bidang, sektor dan penggunaan. 
NUKHBATUL 'ULUM : Jurnal Bidang Kajian Islam

Vol. 4, No. 2 (2018) : Hal. 105-119

Website: https://journal.stiba.ac.id

ISSN : 2685-7537 (online) 2338-5251 (Printed)

Tabel 5. Statistik Deskriptif Indeks Keuangan Inklusif Syariah (d)

\begin{tabular}{|c|c|c|c|c|c|}
\hline \multicolumn{6}{|c|}{ Indeks Aksesibilitas $\left(\mathrm{d}_{1}\right)$} \\
\hline & 2015 & 2016 & 2017 & 2018 & Average \\
\hline Min & - & - & - & - & - \\
\hline $\operatorname{Max}$ & 1.0000 & 1.0000 & 1.0000 & 1.0000 & 1.000 \\
\hline Ave & 0.0449 & 0.0467 & 0.0468 & 0.0478 & 0.047 \\
\hline Stdev. & 0.1694 & 0.1693 & 0.1693 & 0.1691 & 0.169 \\
\hline \multicolumn{6}{|c|}{ Indeks Availabilitas $\left(\mathrm{d}_{2}\right)$} \\
\hline & 2015 & 2016 & 2017 & 2018 & \\
\hline Min & - & - & - & - & - \\
\hline $\operatorname{Max}$ & 1.0000 & 1.0000 & 1.0000 & 1.0000 & 1.000 \\
\hline Ave & 0.1305 & 0.1342 & 0.1434 & 0.1396 & 0.137 \\
\hline Stdev. & 0.1735 & 0.1747 & 0.1747 & 0.1722 & 0.174 \\
\hline \multicolumn{6}{|c|}{ Indeks Penggunaan $\left(\mathrm{d}_{3}\right)$} \\
\hline & 2015 & 2016 & 2017 & 2018 & \\
\hline Min & - & - & - & - & - \\
\hline $\operatorname{Max}$ & 1.0000 & 1.0000 & 1.0000 & 1.0000 & 1.000 \\
\hline Ave & 0.0888 & 0.1506 & 0.1593 & 0.1864 & 0.146 \\
\hline Stdev. & 0.1906 & 0.2272 & 0.2351 & 0.2139 & 0.217 \\
\hline
\end{tabular}

Pada sebagian besar provinsi, proporsi jumlah penduduk memiliki potensi untuk mencapai aksesibilitas yang tinggi pada sistem keuangan syariah dengan tersedianya berbagai kantor layanan syariah (availibilitas), namun mereka tidak menggunakan layanan yang ada dengan baik karena adanya kendala berupa kantor cabang yang tidak dapat dijangkau karena tempat tinggal yang begitu terpencil serta kendala fisik dan psikologis. Beberapa literatur telah mengungkapkan bahwa jasa-jasa tersebut tidak digunakan dengan baik, walaupun masyarakat memiliki akses terhadap jasa keuangan (Sarma, 2012). Akibatnya, tingkat rata-rata indeks keuangan inklusif syariah dari dimensi aksesibilitas yang diukur dari rasio jumlah DPK perbankan baik pada Bank Umum Syariah, Unit Usaha maupun Bank Pembiayaan Rakyat
Syariah per 1.000 penduduk miskin dewasa relatif rendah.

Dalam statistik perbankan syariah di Indonesia, kita dapat menemukan bahwa meskipun kantor layanan bank syariah di 33 provinsi Indonesia telah berdiri dan beroperasi, namun jumlah DPK yang mencerminkan kepemilikan rekening baik tabungan maupun deposito masyarakat pada perbankan syariah masih belum merata di seluruh Indonesia.

Seperti yang diindikasikan oleh nilai dimensi aksesibilitas yang rendah, availibilitas yang tinggi cenderung tidak dimanfaatkan secara optimal oleh masyarakat untuk menggunakan jasa keuangan dan perbankan syariah. Masyarakat lebih cenderung menggunakan jasa keuangan informal daripada fasilitas perbankan syariah formal. Peran yang dominan institusi keuangan non-formal di Indonesia, 
NUKHBATUL 'ULUM : Jurnal Bidang Kajian Islam

Vol. 4, No. 2 (2018) : Hal. 105-119

Website: https://journal.stiba.ac.id

ISSN : 2685-7537 (online) 2338-5251 (Printed)

Tabel 6. Peringkat ISFI pada 33 Provinsi di Indonesia

\begin{tabular}{|c|c|c|c|c|c|c|}
\hline Provinsi & 2015 & 2016 & 2017 & 2018 & Average & Kategori \\
\hline Aceh & 0.05 & 0.29 & 0.31 & 0.46 & 0.36 & Medium \\
\hline Bali & 0.06 & 0.08 & 0.08 & 0.09 & 0.08 & Rendah \\
\hline Bangka Belitung & 0.14 & 0.10 & 0.09 & 0.08 & 0.09 & Rendah \\
\hline Banten & 0.18 & 0.14 & 0.15 & 0.14 & 0.15 & Rendah \\
\hline Bengkulu & 0.05 & 0.04 & 0.05 & 0.12 & 0.07 & Rendah \\
\hline DKI Jakarta & 0.62 & 0.83 & 0.86 & 0.86 & 0.85 & Tinggi \\
\hline Gorontalo & 0.02 & 0.02 & 0.02 & 0.04 & 0.03 & Rendah \\
\hline Jambi & 0.07 & 0.07 & 0.08 & 0.11 & 0.09 & Rendah \\
\hline Jawa Barat & 0.40 & 0.41 & 0.41 & 0.12 & 0.31 & Medium \\
\hline Jawa Tengah & 0.15 & 0.24 & 0.25 & 0.08 & 0.19 & Rendah \\
\hline Jawa Timur & 0.20 & 0.24 & 0.25 & 0.08 & 0.19 & Rendah \\
\hline Kalimantan Barat & 0.04 & 0.08 & 0.09 & 0.15 & 0.11 & Rendah \\
\hline Kalimantan Selatan & 0.12 & 0.15 & 0.16 & 0.21 & 0.17 & Rendah \\
\hline Kalimantan Tengah & 0.06 & 0.06 & 0.06 & 0.08 & 0.07 & Rendah \\
\hline Kalimantan Timur & 0.16 & 0.17 & 0.17 & 0.17 & 0.17 & Rendah \\
\hline Kepulauan Riau & 0.14 & 0.15 & 0.14 & 0.17 & 0.15 & Rendah \\
\hline Lampung & 0.08 & 0.05 & 0.05 & 0.05 & 0.05 & Rendah \\
\hline Maluku & 0.01 & 0.01 & 0.01 & 0.02 & 0.01 & Rendah \\
\hline Maluku Utara & 0.05 & 0.05 & 0.08 & 0.09 & 0.08 & Rendah \\
\hline NTB & 0.06 & 0.06 & 0.07 & 0.32 & 0.15 & Rendah \\
\hline NTT & 0.00 & 0.01 & 0.00 & 0.00 & 0.00 & Rendah \\
\hline Papua & 0.00 & 0.01 & 0.01 & 0.00 & 0.01 & Rendah \\
\hline Papua Barat & 0.01 & 0.01 & 0.01 & 0.01 & 0.01 & Rendah \\
\hline Riau & 0.07 & 0.08 & 0.09 & 0.09 & 0.08 & Rendah \\
\hline Sulawesi Barat & 0.01 & 0.01 & 0.01 & 0.04 & 0.02 & Rendah \\
\hline Sulawesi Selatan & 0.05 & 0.10 & 0.10 & 0.10 & 0.10 & Rendah \\
\hline Sulawesi Tengah & 0.03 & 0.03 & 0.03 & 0.06 & 0.04 & Rendah \\
\hline Sulawesi Tenggara & 0.03 & 0.04 & 0.05 & 0.06 & 0.05 & Rendah \\
\hline Sulawesi Utara & 0.03 & 0.03 & 0.03 & 0.03 & 0.03 & Rendah \\
\hline Sumatera Barat & 0.10 & 0.11 & 0.12 & 0.14 & 0.12 & Rendah \\
\hline Sumatera Selatan & 0.04 & 0.07 & 0.08 & 0.09 & 0.08 & Rendah \\
\hline Sumatera Utara & 0.05 & 0.13 & 0.14 & 0.10 & 0.12 & Rendah \\
\hline Yogyakarta & 0.11 & 0.09 & 0.10 & 0.19 & 0.13 & Rendah \\
\hline Average Total & 0.10 & 0.12 & 0.13 & 0.13 & 0.13 & Rendah \\
\hline
\end{tabular}

khususnya pada daerah terpencil, mengindikasikan bahwa pasar keuangan syariah di Indonesia tidak berfungsi dengan baik.

Selanjutnya, pada analisis ISFI Syariah pada 33 provinsi di Indonesia, hasilnya menunjukkan bahwa Provinsi DKI Jakarta dikategorikan sebagai provinsi dengan ISFI yang tinggi dengan nilai average ISFI selama periode 2015-2018 sebesar 0,85. Bahkan pada tahun 2017, provinsi ini mencatat nilia ISFI yang sangat tinggi yaitu sebesar 0,86. Provinsi dengan nilai ISFI medium adalah Jawa Barat dan Aceh. Sedangkan provinsi-provinsi lainnya tergolong pada tingkat ISFI rendah diantaranya adalah Nusa Tenggara Timur, Sulawesi Utara, Sulawesi Tenggara, Sulawesi Tengah, Gorontalo, Jambi, Sulawesi Barat, Kalimantan Barat, Sumatera Selatan, Papua, Papua Barat, Maluku, Maluku Utara, dan lainnya (Lihat Tabel 6). Sebagaimana ditunjukkan oleh total rata-rata ISFI di Indonesia yaitu sebesar 0,13, Indonesia masuk dalam kategori ISFI rendah selama periode penelitian. Seperti yang ditunjukkan pada Tabel 6, sebagian besar provinsi di Indonesia masuk dalam kategori ISFI rendah. Beberapa provinsi yang yang relatif konsisten memiliki nilai ISFI rendah pada tahun 2015-2018 adalah 
Website: https://journal.stiba.ac.id

ISSN : 2685-7537 (online) 2338-5251 (Printed)

Tabel 7. Hasil Estimasi Korelasi ISFI dan Kemiskinan

\begin{tabular}{|c|c|c|c|}
\hline \multicolumn{4}{|c|}{ Correlations } \\
\hline & & ISFI & Kemiskinan \\
\hline \multirow{3}{*}{ ISFI } & $\begin{array}{c}\text { Pearson } \\
\text { Correlation }\end{array}$ & 1 & $-.368^{*}$ \\
\hline & Sig. (2-tailed) & & .035 \\
\hline & $\mathrm{N}$ & 33 & 33 \\
\hline \multirow{3}{*}{ Kemiskinan } & $\begin{array}{c}\text { Pearson } \\
\text { Correlation }\end{array}$ & $-.368^{*}$ & 1 \\
\hline & Sig. (2-tailed) & .035 & \\
\hline & $\mathrm{N}$ & 33 & 33 \\
\hline
\end{tabular}

Sumber : Hasil olah data

umumnya provinsi di Pulau Sulawesi, Kalimantan, Maluku, Nusa Tenggara, Papua dan sebagian Sumatera. Lebih lanjut, meskipun tidak banyak provinsi dengan ISFI yang tinggi, tetapi Indonesia secara umum menunjukkan kinerja yang baik dan optimis dalam hal inklusifitas sektor keuangan syariah selama periode tersebut. Terdapat level transisi pada sebagian besar provinsi di Indonesia dari ISFI yang rendah ke ISFI yang lebih tinggi.

Dalam mengukur hubungan antara indeks keuangan inklusif syariah, kemiskinan dan kesenjangan ekonomi, penelitian ini mengestimasi hubungan tersebut dengan teknik pearson correlation.

Hasil estimasi pada Tabel 7 menunjukkan bahwa para periode 2015-2018, average keuangan inklusif syariah pada 33 provinsi di Indonesia berkorelasi negatif dan signifikan terhadap tingkat kemikinan. Nilai koefisien korelasi sebesar -0.368 dengan signifikansi 0.035 (lebih kecil dari alpha 0.05) menunjukkan adanya hubungan yang nyata di antara keduanya. Artinya, ketika inklusi keungan syariah naik, maka tingkat kemiskinan cenderung akan menurun. Dengan kata lain, daerah yang memiliki indeks keuangan inklusif yang tinggi, cenderung memiliki tingkat kemiskinan yang rendah.

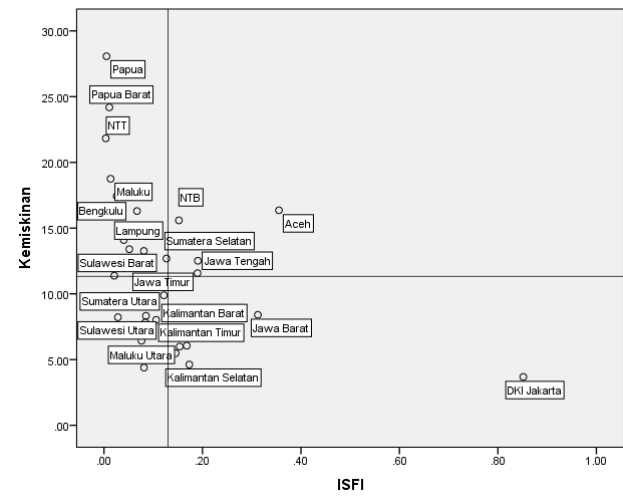

Sumber: hasil olah data

\section{Grafik 2. Scatter Plot nilai ISFI dan Kemiskinan}

Berdasarkan Scatter Plot di atas, penelitian ini mematok titik pada nilai ISFI dan Kemiskinan pada masingmasing 33 provinsi tersebut. Umumnya, provinsi dengan ISFI yang tinggi dan medium dapat dianalogikan relatif memiliki tingkat kemiskinan yang rendah. Provinsi DKI Jakarta dan Jawa Barat yang memiliki nilai ISFI yang relatif tinggi memiliki tingkat kemiskinan di bawah rata-rata. Sama halnya dengan provinsi yang memiliki 
Website: https://journal.stiba.ac.id

ISSN : 2685-7537 (online) 2338-5251 (Printed)

ISFI yang rendah juga memiliki tingkat kemiskinan yang relatif tinggi di atas rata-rata seperti Papua, Papua Barat, Nusa Tenggara Timur, Maluku Utara dan lainnya.

\section{PENUTUP}

Hasil penelitian ini menunjukkan bahwa Indonesia masuk dalam kategori ISFI rendah selama tahun 2015-2018. Secara umum, keuangan inklusif syariah di Indonesia utamanya ditentukan oleh dimensi pengunaan dan availabilitas. Sementara dimensi aksesibilitas hanya memiliki proporsi yang relatif kecil dibanding keduanya. Temuan ini bermakna bahwa kelompok masyarakat tidak sepenuhnya menggunakan jasa keuangan syariah formal, khususnya, sebagai sumber keuangan dan pembiayaan utama. Pengambil kebijakan perlu mengupayakan agar jumlah simpanan/tabungan atau DPK khususnya pada kawasan timur Indonesia dapat ditingkatkan. Provinsi DKI Jakarta dikategorikan sebagai provinsi dengan ISFI yang tinggi dengan nilai average ISFI selama periode 2015-2018 sebesar 0,85. Provinsi dengan nilai ISFI medium adalah Jawa Barat dan Aceh. Sementara provinsiprovinsi lainnya tergolong pada tingkat ISFI rendah.

Selain itu, dari hasil analisis kuantitatif, penelitian ini juga menemukan bahwa inklusifitas keuangan syariah dan tingkat kemiskinan memiliki hubungan yang negatif dan signifikan. Umumnya, provinsi dengan tingkat inklusifitas keuangan syariah yang relatif tinggi dapat dianalogikan relatif memiliki tingkat kemiskinan yang rendah. Sama halnya dengan provinsi yang memiliki tingkat inklusifitas keuangan syariah yang rendah memiliki tingkat kemiskinan yang relatif tinggi seperti Papua, Papua Barat, Nusa Tenggara Timur, Maluku Utara dan lainnya. Untuk penelitian berikutnya, disarankan untuk memperluas objek pengukuran tingkat inklusifitas pada sektor ekonomi atau keuangan syariah lainnya di Indonesia seperti saham syariah, obligasi syariah (sukuk), dan lainnya.

\section{DAFTAR PUSTAKA}

Bank Indonesia. Booklet Financial Inclusion. Jakarta: Bank Indonesia. 2014

Demirgüç-Kunt, A. and L. Klapper. Measuring Financial Inclusion: The Global Findex Database. Policy Research Working Paper, 6025. 2012

Demirgüç-Kunt, A., T. Beck and P. Honohan. Finance for All? Policies and Pitfalls in Expanding Access. Washington D.C.: A World Bank Policy Research Report. 2008

Gupta, Anurag, et al. Financial Inclusion and Human Development: A State-Wise Analysis from India. International Journal of Economics, Commerce and Management, United Kingdom Vol. II, Issue 5, 2014. 2014

Sanjaya, I Made dan Nursechafia. Keuangan inklusif dan Pertumbuhan Inklusif: Analisis Antar Provinsi di Indonesia. Buletin Ekonomi Moneter dan Perbankan, Volume 18, Nomor 3, Januari 2016. 2016

Sarma, M. Index of Financial Inclusion - A Measure of Financial Sector Inclusiveness. Berlin Working Papers on Money, Finance, Trade and Development, No.7, p.1-34. 2012

Sarma, M. Index of Financial Inclusion - A measure of financial sector 
NUKHBATUL 'ULUM : Jurnal Bidang Kajian Islam

Vol. 4, No. 2 (2018) : Hal. 105-119

Website: https://journal.stiba.ac.id

ISSN : 2685-7537 (online) 2338-5251 (Printed)

inclusiveness. Berlin Working Papers on Money, Finance, Trade and Development, No.7, p.1-34. 2012

Sarma, M., and J. Pais. Financial Inclusion and Development: A Cross Country Analysis. Paper Presented at the Conference on Equality, Inclusion and Human Development organized by HDCA and IHD, New Delhi. 2008 